\title{
The Intrinsic Relationship Between Color Variation and Performances of the Deteriorated Aviation Lubrication Oil
}

\author{
Jun $\mathrm{Ma}^{1}$, Shaojun Ruan ${ }^{1}$, Jianqiang $\mathrm{Hu}^{1}$, Yuanbao $\mathrm{Sun}^{1}$, Yiwei Fei ${ }^{1}$, Xufeng Jiang ${ }^{1}$, Shibao \\ Dong $^{1}$, Teng Chen ${ }^{1}$, and Nan $\mathrm{Wu}^{1}$ \\ ${ }^{1}$ Air Force Logistics College
}

June 2, 2020

\begin{abstract}
Dose the blackened lubrication oil needs to be replaced for flying safety? Since there is very limited room for inaccurate assessment of oil quality due to strict flying safety standards, much aviation lubrication oil is disposed in advance long before their service life. More important, aircrafts still face the fatal challenges from unpredictable lubrication oil deterioration. Color change is surely a significant signal to diagnose the quality of lubrication oils. Based on the colorimeter, the color numbers of the testing lubrication oils are measured in this paper to identify the color variation degree of the oxidized lubrication oils. Then the molecular structures of the oxidized lubrication oils are investigated to find the intrinsic relationship between the oxidation products and color numbers. Based on key performances of the oxidized oil samples, the oil quality is undoubtfully deteriorated which is coincident with the variation of color number. The color numbers of the used aviation lubrication oils could provide an alternative way to readily and quickly measure the decline degree and residual lifetime.
\end{abstract}

\section{The Intrinsic Relationship Between Color Variation and Performances of the Deteriorated Aviation Lubrication Oil}

Jun $\mathrm{Ma}^{1, *}$, Shaojun Ruan ${ }^{1}$, Jianqiang $\mathrm{Hu}^{1}$, Yuanbao $\mathrm{Sun}^{1}$, Yiwei $\mathrm{Fe}^{1}{ }^{1}$, Xufeng Jiang ${ }^{1}$, Shibao Dong ${ }^{1}$, Teng $\mathrm{Chen}^{1}, \mathrm{Nan}_{\mathrm{Wu}}{ }^{1,2, *}$

${ }^{1}$ Air Force Logistics College, Xuzhou, Jiangsu, 221000, P. R. China;

${ }^{2}$ School of Pharmacy, Xuzhou Medical University, Xuzhou, Jiangsu, 221004, P. R. China.

Abstract:Dose the blackened lubrication oil needs to be replaced for flying safety? Since there is very limited room for inaccurate assessment of oil quality due to strict flying safety standards, much aviation lubrication oil is disposed in advance long before their service life. More important, aircrafts still face the fatal challenges from unpredictable lubrication oil deterioration.

Color change is surely a significant signal to diagnose the quality of lubrication oils. Based on the colorimeter, the color numbers of the testing lubrication oils are measured in this paper to identify the color variation degree of the oxidized lubrication oils. Then the molecular structures of the oxidized lubrication oils are investigated to find the intrinsic relationship between the oxidation products and color numbers. Based on key performances of the oxidized oil samples, the oil quality is undoubtfully deteriorated which is coincident with the variation of color number. The color numbers of the used aviation lubrication oils could provide an alternative way to readily and quickly measure the decline degree and residual lifetime.

Keywords:Color Variation; Lubricating Oils; Oxidation Products; Color Number; Molecular Structure

\section{Introduction}


The color darkening process of lubrication oils has been making sense of consumers and researchers out of confusion when makes decisions that the deteriorated oils should be replaced. Especially in the application of aviation lubrication oils, there is very limited room for the inaccurate assessment of the oil quality due to the strict flying safety standards. Many researches of the oils color number have established many interesting assessment standards about our daily life ${ }^{1-4}$. In industrial field, the color index of transformer insulating oil has been considering the very critical in ensuring the safety as well as optimal performance of the equipment ${ }^{5}$. The color of oils could also lead to some important application ${ }^{6}$ which is vital towards our living environment.

To be the important component of effective lubrication system, the aviation lubrication oil is facing the challenge of color change which is usually related to the quality deterioration of the oils. Colorimeter has a long history for measuring the quality of the refined petroleum products since $1933^{7-9}$, which also suggests the color is an important parameter of aviation lubrication oils. As reported by the previous study ${ }^{10-12}$, the molecular structure change and the properties deterioration of the oxidized oil samples are confirmed, which also result in gradually changing of the oxidized oil samples color. However, the intrinsic relationship between the oil molecules (oxidizing products and antioxidants) and the resulting color variation needs to be established which could develop a fast and low-cost strategy to rapidly estimate the oil quality.

On the other hand, the gas chromatography mass spectroscopy (GCMS) is powerful method to be widely applied to determine from the molecular structures ${ }^{13}$ and degradation reactions ${ }^{14,15}$ to oil quality ${ }^{16}$ of the lubrication oils. Based on the conjoint analysis of GCMS and color number, the key performances of the oxidized oil samples including fully formulated aviation lubrication oils and base oils are measured to study the relationship between the color, molecular structure and performances of the oxidized oil samples. Towards a fully formulated aviation lubrication oil, the color number could be an easy-acquired oil quality signal to fast evaluate the residual life of the in-service oil after the relationship between the color, molecular structure and performances of the oxidized oil has been established.

\section{Experimental Section}

Poly- $\alpha$-olefin (PAO, 3 cSt at $100{ }^{\circ} \mathrm{C}$ ) and Di-iso-octyl sebacate (DIOS, 3 cSt at $100{ }^{\circ} \mathrm{C}$ ) base oils are purchased from Shanghai Foxsyn Chemical Science and Technology Co. Ltd. and Shanghai Aladdin Biochemical Technology Co. Ltd., respectively. The 928 and 50-1-4థ aviation lubrication oils are commercially available in the Henan Hangcai Science and Technology Co. Ltd. Antioxidants, including 2,6-butylated hydroxytoluene (T501), N-phenyl-1-naphthylamine (T531) and 4,4-diisooctanyldiphenylamine (Tz516) is purchased from Shanghai Kaiyin Chemicals Co. Ltd. A lab-designed aviation lubrication oil comparative oxidation appliance is made for the oxidation reactions of the oil samples in this paper. The base oils (PAO, DIOS) and aviation lubrication oils (928 and 50-1-4థ) are oxidized in the designed appliance shown in Figure 1 (The detailed information of the appliance is shown in Figure 1s in SI). The experiment conditions including metal sheet, oxidation time and oxidation temperature are adjusted in oxidation reactions to produce the oil specimens with different color numbers.

\section{Hosted file}

image1.emf available at https://authorea.com/users/329070/articles/456165-the-intrinsicrelationship-between-color-variation-and-performances-of-the-deteriorated-aviationlubrication-oil

Figure 1 The lab-designed aviation lubrication oil comparative oxidation appliance

The color number of the oxidized oil samples could be measured by the petroleum products chromometer (SYD-0168, Shanghai Jingxi Instruments Co. Ltd.) that follows the petroleum products color number mensuration standard (SH/T 0168-1992). Differential Scanning Calorimeter (DSC, PerkinElmer DSC 8000) is applied to determine the incipient oxidation temperature (IOT) of the oxidized oil samples. The Gas Chromatography-Mass Spectrometry (GC-MS, PerkinElmer Clarus 680/SQ 8T) in this paper is applied to study the molecular structure of the products in oxidized oil specimens. The total acid number is tested according to GB/T 7304-2014 standard by automatic potentiometric titrator (model: SQ-600), and the 
antiwear properties of the oxidized oil samples are tested according to GB/T 3142 standard by four-ball tester (made in Jinan, model: MRS-10G/P).

\section{Results and discussion}

\subsection{The color number variation of the oxidized oil samples}

The fully formulated aviation lubrication oils, 928 and 50-1-4 , are applied in the oxidation reactions performs in the appliance shown in Figure 1. All of the comparative experiments of 928 and 50-1-4 9 aviation lubrication oils carried out in oil bath at the same time and temperature to produce a same oxidation condition in every single oxidation reaction. After oxidation reaction, the color evolution of the oxidized oil specimens is very clear in Figure 2.

\section{Hosted file}

image2.emf available at https://authorea.com/users/329070/articles/456165-the-intrinsicrelationship-between-color-variation-and-performances-of-the-deteriorated-aviationlubrication-oil

Figure 2 The color evolution of 928 (Left) and 50-1-4థ (Right) aviation lubrication oil oxidized in high purity dry air without metal sheet (the numbers inset in the square pictures are color numbers measured by petroleum products chromometer)

According to the color numbers (shown as numbers inset in pictures of oil samples in Figure 2) measured by the petroleum products chromometer (model: SYD-0168), the 928 and 50-1-49 aviation lubrication oil samples were significantly darkening after oxidized in high purity dry air. As mentioned before, the 928 and $50-1-4 \Phi$ aviation lubrication oil samples were treated in same time and temperature to keep every single experiment in nearly identical circumstances. The oxidized 928 oil samples are presented in the left side of Figure 2, while the oxidized 50-1-4థ oil samples are presented in the right side of Figure 2. Compared with

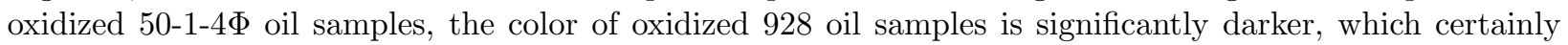
have higher color numbers (the color numbers are shown as the inset numbers in the square pictures of oil samples in Figure 2). The lowest color number of the oxidized 928 oil sample is 9 which is oxidized at $175^{\circ} \mathrm{C}$ for 30 or 60 minutes. However, the color numbers of the oxidized 928 oil samples increase dramatically with increasing oxidation time and temperature. Compared with 928 oil samples, the 50-1-4థ oil samples have relative higher color stability under elevated oxidation conditions. Considering the color numbers of many 928 oil samples exceed the measure range of the petroleum products chromometer, thus, the results from Figure 2 suggest that 928 aviation lubrication oil has relative unstable color stability under the same oxidation condition of 50-1-4 $\Phi$ aviation lubrication oil.

\subsection{The color number influence factors}

Since the color of the oxidized 928 aviation lubrication oil samples is darkening very fast while the oxidation temperature exceeds $200{ }^{\circ} \mathrm{C}$, the color numbers go beyond the measuring range after the oil samples were heated more than 4 hours. On the other hand, the highest operating temperature of $50-1-4 \Phi$ aviation lubrication oil is $175{ }^{\circ} \mathrm{C}$ according to the standard (ГOCT 13076-86). Therefore, the study prefers the oxidation reactions of the base oils under the condition of $175{ }^{\circ} \mathrm{C}$ to investigate the influence of base oils towards the color number of the oxidized oil samples.

\section{Hosted file}

image3.emf available at https://authorea.com/users/329070/articles/456165-the-intrinsicrelationship-between-color-variation-and-performances-of-the-deteriorated-aviationlubrication-oil

Figure 3 The typical molecular structure of PAO and DIOA

\section{Hosted file}


image4.emf available at https://authorea.com/users/329070/articles/456165-the-intrinsicrelationship-between-color-variation-and-performances-of-the-deteriorated-aviationlubrication-oil

Figure 4 The color evolution of the PAO and DIOS oil samples with antioxidants (T501, T531 and Tz516 mentioned in Experimental Section) after oxidized at $175{ }^{\circ} \mathrm{C}$

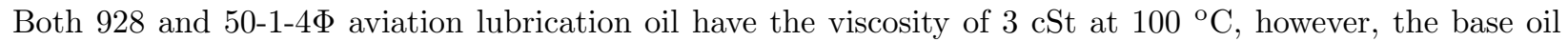
of two lubrication oils is quite different. The base oil of 928 aviation lubrication oil is mainly poly- $\alpha$-olefin (known as PAO), and the base oil of $50-1-4 \Phi$ aviation lubrication oil is synthetic ester (in this paper is di-iso-octyl sebacate, DIOS), as shown in Figure 3.

In the same appliance, the PAO and DIOS (both kinematic viscosity of the base oils is $3 \mathrm{cSt}$ at $100{ }^{\circ} \mathrm{C}$ ) is comparatively oxidized at $175{ }^{\circ} \mathrm{C}$ for the reasons mentioned before. The oxidation temperature is maintained at $175{ }^{\circ} \mathrm{C}$ which is coincident with the maximum operation temperature of 50-1-4థ aviation lubrication oil. As shown in Figure 4, the oxidized PAO and DIOS oil samples with antioxidants (T501, T531 and Tz516 mentioned in Experimental Section) have significant color darkening phenomena after antioxidants were applied in the pure PAO and DIOS. It should be noted that the antioxidants T501, Tz516 are used in 928 and T531 applied in 50-1-4థ aviation lubrication oil, respectively.

\section{Hosted file}

image5.emf available at https://authorea.com/users/329070/articles/456165-the-intrinsicrelationship-between-color-variation-and-performances-of-the-deteriorated-aviationlubrication-oil

Figure 5 The color evolution of PAO and DIOS oil samples with antioxidants (T501, T531 and Tz516) catalytically oxidized by the copper sheet at $175^{\circ} \mathrm{C}$

Due the different antioxidants, color darkening effect could be clearly seen from the oxidation of base oils with antioxidants (Figure 4). The Tz516 has the most obvious color darkening ability according to the color numbers shown inset the relevant oil samples. Without antioxidants, the base oils almost do not change their color numbers in same oxidation condition. The T531 also has similar effect on color change with T501, although in different base oils. Interestingly, the oxidized PAO oil sample which added $1 \%$ Tz516 and $1 \%$ T501 (P516/501) has lower color number (0-12) compared with the color number (11-14) of PAO oil sample with 1\% Tz516 (P516). Especially under shorter oxidation time, the color number of P516/501 is 0 after oxidizing for half an hour while the color number of P516 is 11. Although the color number of P516/501 is sharply increased upto 12 when the oxidation reactions conducted for 8 hours, the color number is also lower than P516. The phenomena suggest that the addition of T501 could significantly reduce the color number of the oxidized oil samples without metal catalyst.

Under catalytical oxidation by $\mathrm{Cu}$ sheet, the color evolution of the base oil samples shown in Figure 5 is darker than the base oil samples oxidized without metal sheet (Figure 4). The phenomena also could be

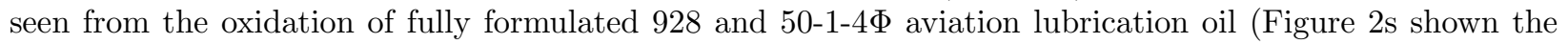
color change of 928 and 50-1-4 $\Phi$ aviation lubrication oil after catalytic oxidized by $\mathrm{Cu}$ sheet from $200{ }^{\circ} \mathrm{C}$ to $290{ }^{\circ} \mathrm{C}$ ). The PAO oil samples added Tz516 has largest color numbers (19-23) compared with other oil samples. Similarly, after T501 and Tz516 were added into PAO oil samples, the color darkening phenomena are inhibiting on a considering degree (color numbers down to 6-15), even the oxidation with the presence of $\mathrm{Cu}$ sheet.

$\mathrm{Cu}$ sheet catalyzed oxidation reactions of the base oil samples without any antioxidants also suggest that metal catalyst could significantly accelerate color darkening (Pure PAO,0-8; Pure DIOS, 0-7) compared with Figure 4 that the color number of Pure PAO and Pure DIOS without $\mathrm{Cu}$ sheet are $0-1$. The PAO and DIOS without antioxidant would demonstrate a relative fast color darkening under $\mathrm{Cu}$ sheet catalytic oxidation reactions. The color numbers of DIOS with T531 also have sharply change oxidized for more than 4 hours 
which also suggest that $\mathrm{Cu}$ sheet catalytic oxidation has greater impact on the color darkening process of the oxidized oil samples.

\subsection{The oxidation products analysis and oxidation mechanism study}

Since the base oils without antioxidants show slight change of color number, this paper focus on the oil samples with antioxidants. The oxidation reactions carried out in the paper could divided as four series experiments (each series has two categories depends on $\mathrm{Cu}$ sheet is applies in experiment or not): the PAO and T501 ( $\mathrm{P}_{501}$, the total ions chromatograms shown in Figure 3s), PAO and Tz516 ( $\mathrm{P}_{516}$, the total ions chromatograms shown in Figure 4s), PAO T501 and Tz516 ( $\mathrm{P}_{501+516}$, the total ions chromatograms shown in Figure 5s), DIOS and T531 ( $\mathrm{D}_{531}$, the total ions chromatograms shown in Figure $\left.6 \mathrm{~s}\right)$. The total ions chromatograms shown in SI give a rough sense of the oxidation products.

After careful analysis, the evidences from Figure 3s-6s show the species of base oils, antioxidants and $\mathrm{Cu}$ sheet catalyst could significantly change the color number of the oxidized oil samples. There are demands for identifying the oxidation products' species and antioxidants to determine the yield of oxidation products and consumption of antioxidants. The oxidation products are too many to list, otherwise a large amount of oxidation chemicals would be resulting in confusion. After extraction, separation and analysis, the typical color materials existing in the oil samples can be distinguished as two categories: color- related-oxidationproducts (CORP) from antioxidants (CORPA) and CORP from base oil (CORPB).

According to the molecular analysis of the typical color related oxidation products with or without $\mathrm{Cu}$ sheet, the typical CORPA and CORPB have considerable amount (have larger peak area) and highly repeatedly shown in their total ions chromatograms could be concluded as follows (Table 1). The listed chemicals (Table 1) that shown as the typical color related oxidation products are the representative substances detected in the oil samples after extraction and separation. It's reasonable that the content of the typical CORPA and CORPB might reflect the color variation of the oxidized oil samples. Generally, the CORPA mainly have the basic molecular structure that similar to the antioxidants and the CORPB have longer alkane chain.

\begin{tabular}{lllll}
\hline $\begin{array}{l}\text { Table 1 The color- } \\
\text { related-oxidation- } \\
\text { products (CROP) } \\
\begin{array}{l}\text { from the oxidized } \\
\text { oil samples }\end{array}\end{array}$ & $\begin{array}{l}\text { Table 1 The color- } \\
\text { related-oxidation- } \\
\text { products (CROP) } \\
\text { from the oxidized } \\
\text { oil samples }\end{array}$ & $\begin{array}{l}\text { Table 1 The color- } \\
\text { related-oxidation- } \\
\text { products (CROP) } \\
\text { from the oxidized } \\
\text { oil samples }\end{array}$ & $\begin{array}{l}\text { Table 1 The color- } \\
\text { related-oxidation- } \\
\text { products (CROP) } \\
\text { from the oxidized } \\
\text { oil samples }\end{array}$ & $\begin{array}{l}\text { Table } 1 \text { The color- } \\
\text { related-oxidation- } \\
\text { products (CROP) } \\
\text { from the oxidized } \\
\text { oil samples }\end{array}$ \\
\hline PAO + T501 & PAO + Tz516 & $\begin{array}{l}\text { PAO +T501+ } \\
\text { Tz516 }\end{array}$ & DIOS + T531 \\
CORPA & 1 & 6 & 10 & 15 \\
& 2 & 7 & 11 & 16 \\
CORPB & 8 & 13 & 17 \\
\hline
\end{tabular}

\section{Hosted file}

image20.emf available at https://authorea.com/users/329070/articles/456165-the-intrinsicrelationship-between-color-variation-and-performances-of-the-deteriorated-aviationlubrication-oil

Figure 6 The relative content of the color-related-oxidation-products from the oxidized oil samples

After the typical color related oxidation products are selected (as shown in Table 1s), the integral area values of the chemicals are calculated and listed in the Table $1 \mathrm{~s}-8 \mathrm{~s}$ according to the Figure $3 \mathrm{~s}-6 \mathrm{~s}$. For ease of reading, the data are converted to Figure 6 which presents the variation trend more intuitive. It should be noted that all of the base oils with antioxidants (T501, Tz516 and T531) would generate more CORP after 
$\mathrm{Cu}$ sheet applied in the reactions. The phenomenon could be easily seen from the Figure $6 \mathrm{c}$ and $6 \mathrm{~d}$, which is the CORP of the oxidized PAO and Tz516, the amount of CORP with $\mathrm{Cu}$ sheet is almost 500 times more than the CORP without $\mathrm{Cu}$ sheet. As shown in the Figure 6, several CORP (4, 7, 12 and 15 in Table 1) sharply increase with increasing oxidation time whether $\mathrm{Cu}$ sheet is applied or not. The chemical formula of the CORP 4 and 12 (actually same chemicals) in Table 1 are mainly the diradical termination reaction products of T501 (shown in Figure 7).However, the CORP 7 and 15 might hard to find suitable reaction mechanism to explain the actually relations occurs in the complex system of PAO with Tz516 and DIOS with T531. As shown in Figure 7, the CORP 4 (or 12) is suggested to be produced by the biradical termination reaction through Figure $7 \mathrm{~b}$ route after the T501 is oxidized by free radicals by Figure 7a route. The hydrogen transfer is easy to occur in the alkane substituted benzoquinone structure because of the conjugated system. Compared with CORPA, the CORPB have relative small amount in oxidized oil samples. In the oxidation reactions catalyzed by $\mathrm{Cu}$ sheet, most $\mathrm{CORPB}$ distinctly increase while the oxidation time was increasing (Table 1s-8s, CORPB 4, 7, 12 and 15). The result is positive for both PAO and DIOS oil samples.

\section{Hosted file}

image21.emf available at https://authorea.com/users/329070/articles/456165-the-intrinsicrelationship-between-color-variation-and-performances-of-the-deteriorated-aviationlubrication-oil

Figure 7 The suggested biradical termination reaction of CORP 4 (or 12) in Table 1

\subsection{The performances of the oxidized oil samples}

Since the kinematic viscosity of the oxidized 928 and 50-1-4Ф aviation lubrication oils shows small variation (Figure 9s) that could be considered within the margin of error of Ukrainian-style viscometer applied in this paper. However, the kinematic viscosity of the oxidized 928 oil samples has higher values $\left(\sim 4 \mathrm{~mm}^{2} / \mathrm{s}\right)$ compared with the oxidized $50-1-4 \Phi$ oil samples $\left(\sim 3 \mathrm{~mm}^{2} / \mathrm{s}\right)$.

Table 2 The relationship between the residual content of antioxidants and residual incipient oxidation temperature (IOT) of the 928 and 50-1-4 $\Phi$ aviation lubrication oil samples oxidized for 2 hours

Oxidation

temperature

\begin{tabular}{llllll}
$\left({ }^{\circ} \mathrm{C}\right)$ & 928 & 928 & & $50-1-4 \Phi$ & $50-1-4 \Phi$ \\
\hline & $\mathrm{T} 501 / \%$ & $\mathrm{Tz} 516 / \%$ & $\mathrm{IOT} /{ }^{\circ} \mathrm{C}$ & $\mathrm{T} 531 / \%$ & $\mathrm{IOT} /{ }^{\circ} \mathrm{C}$ \\
Untreated & 1.541 & 1.516 & 264.1 & 0.564 & 269.7 \\
210 & 0.722 & 1.409 & 263.3 & 0.377 & 263.5 \\
230 & 0.318 & 1.317 & 261.2 & 0.241 & 251.4 \\
250 & 0.437 & 1.295 & 259.4 & 0.203 & 252.0 \\
270 & 0.311 & 1.309 & 259.1 & 0.113 & 249.9 \\
290 & 0.189 & 1.182 & 254.5 & 0.098 & 246.8 \\
\hline
\end{tabular}

After the measurement of the residual antioxidants of the oxidized oil samples, the oxidized oil samples were testing for their residual initial oxidation temperature (IOT, shown in Table 2). It is easy to find the residual IOT values decrease with decreasing residual antioxidants for their antioxidation ability gradually decreased. At the same time, the color number of the oxidized fully formulated aviation oil samples (Figure 2s) dramatically increased for the rapidly increasing color-related-oxidation-products shown in Table 1. As discussed above, most color-related-oxidation-products are generated from the reaction of antioxidants.

Table 3 The total acid number of the 928 and 50-1-4Ф aviation lubrication oil samples oxidized for 2 hours $(\mathrm{mgKOH} / \mathrm{g})$ 


\begin{tabular}{lll}
\hline Oxidation temperature $\left({ }^{\circ} \mathrm{C}\right)$ & 928 & $50-1-4 \Phi$ \\
\hline Untreated & 0.03 & 0.04 \\
210 & 0.43 & 0.31 \\
230 & 1.07 & 0.95 \\
250 & 1.13 & 1.61 \\
270 & 1.42 & 1.91 \\
290 & 2.31 & 3.69 \\
\hline
\end{tabular}

\section{Hosted file}

image22.emf available at https://authorea.com/users/329070/articles/456165-the-intrinsicrelationship-between-color-variation-and-performances-of-the-deteriorated-aviationlubrication-oil

Figure 8 The diameter of steel ball wear scar while the 928 and 50-1-4Ф aviation lubrication oil samples (oxidized for 2 hours) are applied

As expected, the total acid number (TAN, shown in Table 3) of the oxidized 928 and 50-1-4Ф aviation lubrication oils were increasing with higher oxidation temperature, which coincident with the anti-wear testing shown in Figure 8. Both the TAN and diameter of wear scar would be promoted rapidly while the oxidation temperature exceeds $230{ }^{\circ} \mathrm{C}$. The oil quality of the oxidized oil samples is undoubtedly deteriorated in the oxidation reactions. As described before, the color number of the oxidized oil samples might provide a readily method to identify the oil quality through the direct measurement of the color-related-oxidationproducts. As shown in Figure 2s, the methods still need improvement to elevate the resolution ratio and measurement range. More sophisticated and effective testing strategies about designment on more effective filtration and thinner oil pipe might be required to realize the above demands.

\section{Conclusions}

According to the color investigation of the oxidized lubrication oil samples, we found that the color of the oxidized oil samples is mainly determined by the amount and species of antioxidants and oxidation conditions (including catalysts, temperature, time). Based on the incipient oxidation temperature, total acid number and tribological performances tests, the overall performances of the fully formulated aviation lubrication oil (T501 and Tz516 are used as antioxidants) would be remarkably reduced when the color number exceeds 23 at $250{ }^{\circ} \mathrm{C}$ oxidized for 2 hours. In the same case of fully formulated aviation lubrication oil with T531 used as antioxidants, the performances would decrease significantly when the color number exceeds 21 under same reaction conditions. The color number is proved that have potential practical applications in the field of fast determination of the quality and residual lifetime of the in-service aviation lubrication oil.

\section{Acknowledgments}

This work was supported and funded by National Natural Science Foundation of China (Granted No. 51575525), Natural Science Foundation of Jiangsu Province for Young Scholars (Granted No. BK20180180), Natural Science Foundation of Jiangsu Province (Grant No. BK20161188) and the Air Force Logistics College Youth Fund (Grant No. KY2018D031C).

\section{References}

1. Samaram, S.; Mirhosseini, H.; Tan, C. P.; Ghazali, H. M., Ultrasound-assisted extraction and solvent extraction of papaya seed oil: Crystallization and thermal behavior, saturation degree, color and oxidative stability. Industrial Crops and Products 2014,52, 702-708.

2. Barbut, S.; Youssef, M. K., Effect of Gradual Heating and Fat/Oil Type on Fat Stability, Texture, Color, and Microstructure of Meat Batters. Journal of Food Science 2016, 81, (9), C2199-C2205. 
3. de Almeida, M. M. C.; Francisco, C. R. L.; de Oliveira, A.; de Campos, S. S.; Bilck, A. P.; Fuchs, R. H. B.; Gonçalves, O. H.; Velderrama, P.; Genena, A. K.; Leimann, F. V., Textural, Color, Hygroscopic, Lipid Oxidation, and Sensory Properties of Cookies Containing Free and Microencapsulated Chia Oil. Food and Bioprocess Technology 2018, 11, (5), 926-939.

4. Muzzio, C. R.; Díaz, R. J.; Dini, N. G., In-line measurement of sunflower oil color in the Lovibond scale using a low-cost robust device. Journal of Food Engineering 2014, 120, 88-93.

5. Leong, Y. S.; Ker, P. J.; Jamaludin, M. Z.; Nomanbhay, S. M.; Ismail, A.; Abdullah, F.; Looe, H. M.; Lo, C. K., UV-Vis Spectroscopy: A New Approach for Assessing the Color Index of Transformer Insulating Oil.Sensor 2018, 18, (7), 2175.

6. Yong, J.; Chen, F.; Yang, Q.; Bian, H.; Du, G.; Shan, C.; Huo, J.; Fang, Y.; Hou, X., Oil-Water Separation: A Gift from the Desert.Advanced Materials Interfaces 2016, 3, (7), 1500650.

7. Story, B. W.; Kalichevsky, V. A., Photoelectric Colorimeter for Measuring Color Intensities of Liquid Petroleum Products.Industrial \&3 Engineering Chemistry Analytical Edition1933, 5, (3), 214-217.

8. Lykken, L.; Treseder, R. S.; Zahn, V., Colorimetric Determination of Phenols. Application to Petroleum and Allied Products. Industrial \& Engineering Chemistry Analytical Edition 1946, 18, (2), 103-109.

9. Oje, O.; Ubani, C.; Onwurah, I., Variation in the Carbon (C), Phosphorus (P) and Nitrogen (N) Utilization during the Biodegradation of Crude Oil in Soil. Journal of Petroleum and Environmental Biotechnology 2018, $6,(2), 1000206$.

10. Fei, Y.; Wu, N.; Ma, J.; Hao, J., Thermal cracking of poly $\alpha$-olefin aviation lubricating base oil. IOP Conference Series: Earth and Environmental Science 2018, 121, (2), 022031.

11. Ma, J.; Fei, Y.; Wu, N.; Sun, S.; Wang, Y., The influence of high temperature oxidation on molecular structure and performance of aviation base oils. Asia-Pac. J. Chem. Eng. 2018, 14, (1), e2273.

12. Wu, N.; Zong, Z.; Fei, Y.; Ma, J.; Guo, F., Thermal Degradation of Aviation Synthetic Lubricating Base Oil. Petroleum Chemistry2018, 58, (3), 250-257.

13. Gough, M. A.; Rowland, S. J., Characterization of unresolved complex mixtures of hydrocarbons in petroleum. Nature 1990, 344, 648-650.

14. Santos, J. C. O.; Santos, I. M. G.; Souza, A. G., Thermal Degradation Process of Synthetic Lubricating Oils: Part I-Spectroscopic Study. Petroleum Science and Technology2015, 33, (11), 1238-1245.

15. Wang, J.; Zhang, B.; Zhong, Z.; Ding, K.; Deng, A.; Min, M.; Chen, P.; Ruan, R., Catalytic fast co-pyrolysis of bamboo residual and waste lubricating oil over an ex-situ dual catalytic beds of $\mathrm{MgO}$ and HZSM-5: Analytical PY-GC/MS study. Energy Conversion and Management 2017, 139, 222-231.

16. Yang, C.; Yang, Z.; Zhang, G.; Hollebone, B.; Landriault, M.; Wang, Z.; Lambert, P.; Brown, C. E., Characterization and differentiation of chemical fingerprints of virgin and used lubricating oils for identification of contamination or adulteration sources. Fuel2016, 163, 271-281. 